\title{
Lateral Growth of Three-Dimensional Turbidity Current for Supercritical Initial Conditions
}

\author{
Mohammad Reza MOOSSAVI-HEKMATI, Mohammad NAJAFI
}

\begin{abstract}
The aim of this paper is to investigate the lateral growth of an unsteady turbulent inclined turbidity current. To do so, the Buckingham $\Pi$ theorem together with a dimensional analysis are implemented to derive two appropriate relations, one of which relates the current width to the current length and the other one expresses the current width in terms of time. The coefficients of the two relations are determined experimentally. Based on the results obtained, three different regimes namely, inertiaviscous as the first regime, buoyancy-viscous, and gravity-viscous as the second and third regimes are distinguished within the current. The experimental results indicate that the lateral growth rate in the first regime is less than that in the second one. Based on the results obtained, the lateral growth in some particular regions is independent of slope, concentration, and volumetric flow rate variations.
\end{abstract}

Keywords: lateral growth; supercritical initial conditions; turbidity current; turbulence; unsteady

\section{INTRODUCTION}

Many geophysical flows can be classified as gravity or density currents as they occur due to a density difference with the surrounding environment. In atmospheric gravity currents, such as sea-breeze fronts or thunderstorm outflows, the density difference is typically caused by a temperature difference between a dense spreading cold front and relatively warm less dense ambient air [1,2]. Gravity or density currents are flows driven by density differences. Turbidity currents are types of gravity currents where the driving force gained from the suspended sediment sand turbid water is greater than that of the clear water above it. Geological observations show turbidity currents are some common forms of sediment transport in many sedimentary basins (lakes, reservoirs, seas, oceans, etc.) [3]. Turbidity current is also defined as particle-laden underflows that occur in lakes and oceans bottoms. These currents play an important role in transporting fluvial littoral and shelf sediments into deep ocean environments [4]. Unfortunately, natural turbidity currents are hard to observe and study, owing to their large-scale and often destructive nature [4]. Therefore, one of the best means for understanding the hydrodynamics of gravity currents is experimental study. A large number of experimental studies on density currents can be found in the literature [5-25].

Turbidity currents in the ocean are known to be a maker of submarine canyons [4, 26]. Sediment deposition in reservoirs reduces the flood-control benefits downstream and the capacity of water storage increase flooding upstream due to the streambed aggregation in a deltaic region which causes impairment of navigability, sediment entrainment in hydropower equipment, blockage of gates and intakes, etc. [27].

Stagnaro and Pittaluga [28] presented a series of detailed experimental observations of saline and turbidity currents flowing in a straight channel. Experiments were performed by continuously feeding the channel with a dense mixture until a quasi-steady configuration was attained. Their longitudinal velocity profiles were measured using an ultrasound Doppler velocity profiler. They also measured the density of the mixture using a rake of siphons sampling at different heights from the bottom in order to obtain vertical density distributions in a cross section where the flow had already attained a quasiuniform configuration. The distributions turned out to be influenced by the Reynolds number of the flow, the relative bed roughness, and the presence of sediment in suspension. Unexpectedly, the densimetric Froude number of the current turned out to have no influence on the dimensionless velocity profiles.

The first set of experiments on a three-dimensional density current was conducted by Fietz and Wood [29]. They suggested that, not too close to its source, the width of the current grows linearly at an angle which is larger for a turbulent current than that for an equivalent laminar one. Alavian [30] investigated three-dimensional density currents of salt solution for slopes of 5, 10, and 15 degrees. He showed that the lateral spreading of the density current is dependent on the primary buoyancy flux and the slope of the bottom. He observed that the width of the current tends to become nearly constant at a certain distance from the origin, about 30 times greater than the initial width at the source. The final width was found to be influenced by larger buoyancy fluxes and smaller bottom slopes. Tsihrintzis [31], based on a large number of experiments, arrived at similar conclusions as those of Alavian's concerning the growth of the current width. Christodoulou and Tzachou [32], suggested a nearly linear dependence of the final width of the current on the length scale $\left(B^{2} / g^{\prime 3}\right)^{1 / 5}$, where $B$ is the buoyancy flux and $g$ is the gravity acceleration. The above length scale can be written equivalently as $l=\left(Q^{3} / B\right)^{1 / 5}$, where $Q$ is the flow rate and $B$ is the buoyancy flux. The same scale was used, recently, by Choi [33] for expressing his experimental results for the maximum width of unsteady currents as a logarithmic function of time. Tsihrintzis and Alavian [34] investigated geometric and kinematic behaviour of two- and three-dimensional negative buoyancy gravity plume spreading on a steep sloping surface in a laboratory tank. They presented simple analytical expressions based on the balance of driving and resisting forces, i.e., gravity, buoyancy, inertia, and friction, in both the longitudinal and latitudinal flow directions. They concluded that the analytical expressions for the spreading depend on the bottom slope, the initial buoyancy flux, the Richardson number, and the geometry of the plume at the source. Also, it was shown that the mathematical solution was in agreement with the 
measured experimental data. Based on their results, for different slopes, Tab. 1 for different spreading regimes was constructed.

Table 1 Spreading regimes for two-and three-dimensional gravity plumes [34]

\begin{tabular}{|c|c|c|}
\hline Slope & Inlet flow & Regime \\
\hline \multirow{4}{*}{ Horizontal } & Subcritical & $\begin{array}{c}\text { Buoyancy-Inertia } \\
\text { Buoyancy-Viscous }\end{array}$ \\
\cline { 2 - 3 } & Supercritical & $\begin{array}{c}\text { Inertia-Viscous } \\
\text { Buoyancy-Viscous }\end{array}$ \\
\hline \multirow{5}{*}{ Mild } & Subcritical & $\begin{array}{c}\text { Buoyancy-Inertia } \\
\text { Buoyancy-Viscous } \\
\text { Gravity-Viscous }\end{array}$ \\
\cline { 2 - 3 } & Supercritical & $\begin{array}{c}\text { Inertia-Viscous } \\
\text { Buoyancy-Viscous } \\
\text { Gravity-Viscous }\end{array}$ \\
\hline & Subcritical & $\begin{array}{c}\text { Buoyancy-Inertia } \\
\text { Gravity-Inertia } \\
\text { Gravity-Viscous }\end{array}$ \\
\cline { 2 - 3 } & Supercritical & $\begin{array}{c}\text { Inertia-Viscous } \\
\text { Gravity-Viscous }\end{array}$ \\
\hline
\end{tabular}

Christodoulou [35] examined the rate of lateral growth of three-dimensional bottom-attached density currents for the bottom slopes ranging between $2^{\circ}$ and $15^{\circ}$, for the flow rate $Q$ between $25 \times 10^{-6}$ and $200 \times 10^{-6}$ $\mathrm{m}^{3} / \mathrm{s}$, and the relative density difference $\Delta \rho / \rho$ between 0.005 and 0.038 . Based on his experimental results, he found the width $b$ of the three- dimensional density current can be expressed in non-dimensional form in terms of distance $x$ from the source as $b / l \sim(x / l)^{n}$, where $l=\left(Q^{3} / B\right)^{1 / 5}$ is called buoyancy length scale and $b$ is the width that is normalized with respect to the buoyancy length scale [35].

Choi and Garcia [36] investigated the spreading law for sediment-laden gravity currents. They employed saline density currents as surrogates for fine-grained turbidity flows. They used dimensional analysis to develop a simple expression for lateral spreading rates of two-dimensional flows on sloping beds. The characteristic length and time scales were determined by the volume flux and buoyancy flux at the inlet. By knowing the initial width of the flow, the spreading law was used to estimate the maximum width of the current at different times and at different longitudinal spreading rates. A regression analysis was performed to obtain a logarithmic relationship between the maximum half width and time [36].

Based on a thorough literature search conducted, there is quite a dearth of experimental as well as theoretical work in unsteady three- dimensional turbidity current arena, in particular, for unsteady and turbulent conditions. In this study, efforts are undertaken to investigate the lateral growth of a turbulent unsteady supercritical inclined turbidity current. The study employs the balance of forces using the Buckingham $\pi$ theorem to derive some dimensionless relations for a better understanding of a turbulent turbid current propagating within another medium. The present study involves both experimental and theoretical work, and considers only the lateral growth portion of the turbid current for unsteady condition.

\section{EXPERIMENTAL SETUP AND PROCEDURE 2.1 Experiments}

The experimental setup used for the work of this project is shown in Fig. 1 and consists of a main channel (filled with tap water) having a $12 \mathrm{~m}$ length, $1,5 \mathrm{~m}$ width, and $0,6 \mathrm{~m}$ height. Inside the main channel at its upper end, a housing of $0,15 \mathrm{~m}$ length, 1,5 $\mathrm{m}$ width, and 0,6 $\mathrm{m}$ height is located as shown in the figure. It is noted here that, similar experimental setup using clear water has also been used for turbidity current or density current simulation by many researchers in the field [1, 4, 6-10, 23, 27-36].

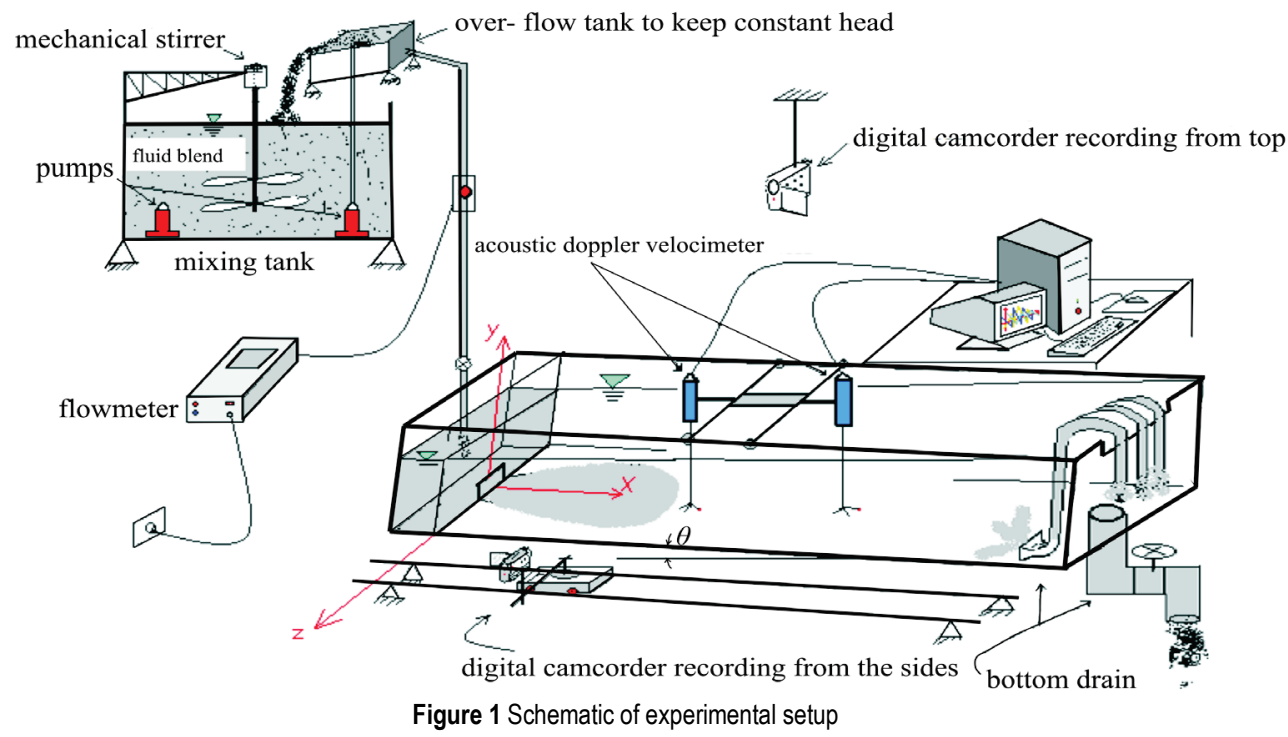

A mixing tank made of a cylindrical rust-proof stainless-steel having a volume of $2 \mathrm{~m}^{3}$ is located at the upper end above the main channel. This reservoir is used for making different fluid blends. Clone with a density of $2650 \mathrm{~kg} / \mathrm{m}^{3}$ is blended with tap water to make the mixture used in the present work. The average size of the clone particles used is about 20 microns. To furnish a fixed head to have a constant volume flux rate for the blend, a small stainless-steel over-flow tank (shown in Fig. 1) having dimensions of $0,3 \mathrm{~m}$ in height, $0,5 \mathrm{~m}$ in length, and $0,5 \mathrm{~m}$ in width is designed and placed on top of the mixing tank as shown in the Fig. 1.

The mixture of clone and water is pumped by a small submersible pump within the mixing tank into the over- 
flow tank to produce the fixed head. The mixture then enters the upper portion of the main channel through a connecting pipe and a flow meter as shown in Fig. 1. The remaining blend within the over- flow tank goes back into the mixing tank. Another submersible pump and a small stirrer are placed inside the mixing tank to prevent particles sedimentation within the mixing tank. The mixture stream (turbidity current) containing the caolen particles passes through an underpass trap door $(0,1 \mathrm{~m}$ length and 0,125 m height) of the housing ( Fig. 1) and enters the main channel and flows underneath the tap water. The stream, then, travels all the way underneath the clear water to the end of the channel where it drains out (Fig. 1).

The slope of the main channel $(\theta)$ can vary by a hydraulic jack to a maximum of $3,5 \%$. The experimental runs are performed for three slopes of 1,2 , and $3 \%$. In order to measure the volume flux rate of the flow, an ultrasonic volume flux meter (Greyline Company, Canada-model DMF) with an accuracy of $0,01 \mathrm{lit} / \mathrm{min}$ $\left(1,66 \times 10^{-7} \mathrm{~m}^{3} / \mathrm{s}\right)$ is used. The runs are performed for three volume flux rates of 10,15 , and $20 \mathrm{lit} / \mathrm{min}\left(1,66 \times 10^{-4}\right.$, $2,50 \times 10^{-4}$, and $\left.3,33 \times 10^{-4} \mathrm{~m}^{3} / \mathrm{s}\right)$. A digital camcorder is used to measure the latitudinal and longitudinal spreading of the turbidity current within the main channel, and to observe the stream head. The channel framework is made of glassy walls which enable a camera to record the activities taking place near the side walls. Along one of the sides of the main channel, a metal rail is set up to let the recording carriage move on it, recording the longitudinal spreading of the turbidity current, the depth of the stream, and the flow front, all with an accuracy of 0,01 seconds. To measure the latitudinal and longitudinal spreadings of the flow, the main channel floor is gridded as shown in Fig. 2. Another camera is located over the channel for recording the lateral spreading of the density current. In this experiment, three different concentrations, volume flux rates, and main channel slopes are used to observe their effects on the lateral spreading of the density current, the current velocity, and the thickness of the developed sediment.

\subsection{Measurements}

Fig. 2 shows the maximum lateral $(b)$ and longitudinal $(x)$ growths of a turbidity current, at any instant of time for each experimental run.

It is noted here that, for the latitudinal as well as longitudinal growths of turbidity current measurements, Tsihrintzis et al. [34] and some other investigators used the same method.

Tab. 2 shows the conditions at which each experimental run is taken place. In this table $S$ represents the main channel slope, $C_{0}$ denotes initial (or inlet) mixed weight concentration defined by,

$C_{0}=\frac{w_{c}}{w_{w}} \times 100$

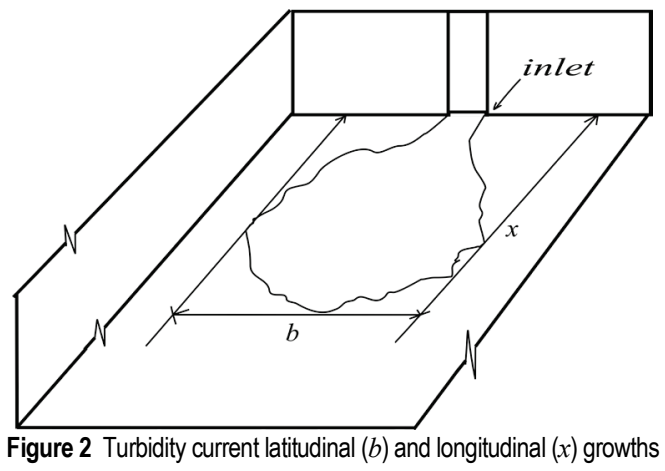

Table 2 Initial values of parameters used in experimental runs

\begin{tabular}{|c|c|c|c|c|c|c|}
\hline RUN No. & $S \%$ & $C_{0} \%$ & $Q_{0}\left(\mathrm{~m}^{3} / \mathrm{s}\right)$ & $R e_{0}$ & $R i_{0}$ & $T\left({ }^{\circ} \mathrm{C}\right)$ \\
\hline 3 & 3 & 0,5 & $1,66 \times 10^{-4}$ & 1532,32 & 0,0262 & 17 \\
\hline 4 & 3 & 0,5 & $2,50 \times 10^{-4}$ & 2297,91 & 0,0118 & 17 \\
\hline 5 & 3 & 0,5 & $1,66 \times 10^{-4}$ & 1532,32 & 0,0262 & 17 \\
\hline 6 & 3 & 1 & $4,00 \times 10^{-5}$ & 366,70 & 0,5782 & 17 \\
\hline 7 & 3 & 1 & $2,50 \times 10^{-4}$ & 2269,94 & 0,0147 & 16,5 \\
\hline 8 & 3 & 1 & $1,66 \times 10^{-4}$ & 1571,04 & 0,0331 & 18 \\
\hline 9 & 3 & 1 & $8,33 \times 10^{-5}$ & 784,93 & 0,1326 & 18 \\
\hline 10 & 3 & 1 & $1,00 \times 10^{-4}$ & 929,93 & 0,0921 & 18,5 \\
\hline 11 & 3 & 0,5 & $8,33 \times 10^{-5}$ & 765,58 & 0,0105 & 17 \\
\hline 12 & 3 & 1,5 & $3,33 \times 10^{-4}$ & 2990,93 & 0,0100 & 16 \\
\hline 13 & 3 & 1,5 & $2,50 \times 10^{-4}$ & 2242,64 & 0,0177 & 16 \\
\hline 14 & 3 & 1,5 & $1,66 \times 10^{-4}$ & 1450,66 & 0,0406 & 15 \\
\hline 15 & 3 & 1,5 & $3,33 \times 10^{-4}$ & 2759,15 & 0,0099 & 13 \\
\hline 16 & 2 & 0,5 & $1,66 \times 10^{-4}$ & 1450,66 & 0,0266 & 15 \\
\hline 17 & 2 & 0,5 & $2,50 \times 10^{-4}$ & 2242,64 & 0,0117 & 16 \\
\hline 18 & 2 & 0,5 & $3,33 \times 10^{-4}$ & 2990,94 & 0,0065 & 16 \\
\hline 19 & 2 & 1 & $1,66 \times 10^{-4}$ & 1520,83 & 0,0336 & 17 \\
\hline 20 & 2 & 1 & $2,50 \times 10^{-4}$ & 2191,89 & 0,0147 & 15 \\
\hline 21 & 2 & 1 & $3,33 \times 10^{-4}$ & 2923,25 & 0,0082 & 15 \\
\hline 22 & 2 & 1 & $2,50 \times 10^{-4}$ & 2269,94 & 0,0147 & 16,5 \\
\hline 23 & 2 & 1,5 & $1,66 \times 10^{-4}$ & 1502,32 & 0,406 & 16,5 \\
\hline 24 & 2 & 1,5 & $2,50 \times 10^{-4}$ & 2269,94 & 0,0177 & 16,5 \\
\hline 25 & 2 & 1,5 & $3,33 \times 10^{-4}$ & 1502,32 & 0,0406 & 16,5 \\
\hline 26 & 1 & 0,5 & $1,66 \times 10^{-4}$ & 1484,25 & 0,0265 & 16 \\
\hline 27 & 1 & 0,5 & $1,66 \times 10^{-4}$ & 1484,25 & 0,0265 & 16 \\
\hline 28 & 1 & 0,5 & $2,50 \times 10^{-4}$ & 2242,64 & 0,0116 & 16 \\
\hline 29 & 1 & 1 & $1,66 \times 10^{-4}$ & 1487,14 & 0,0335 & 15,8 \\
\hline 30 & 1 & 0,5 & $3,33 \times 10^{-4}$ & 2878,55 & 0,0065 & 14,5 \\
\hline 31 & 1 & 0,5 & $3,33 \times 10^{-4}$ & 2797,83 & 0,0065 & 13,5 \\
\hline 32 & 1 & 1 & $2,50 \times 10^{-4}$ & 2127,68 & 0,0147 & 14 \\
\hline 33 & 1 & 1 & $3,33 \times 10^{-4}$ & 2990,94 & 0,0083 & 16 \\
\hline 34 & 1 & 1,5 & $1,66 \times 10^{-4}$ & 1559,26 & 0,0406 & 18 \\
\hline 35 & 1 & 1,5 & $2,50 \times 10^{-4}$ & 2242,64 & 0,0177 & 16 \\
\hline 36 & 1 & 1,5 & $3,33 \times 10^{-4}$ & 3027,34 & 0,0100 & 16,5 \\
\hline
\end{tabular}

where $w_{\mathrm{c}}$ and $w_{\mathrm{w}}$ are the weight of the water and clone used, respectively. In this table $Q_{0}$ is initial volume flux, $R e_{0}$ is the initial flow Reynolds number defined as,

$R e_{0}=\frac{u_{0} h_{0}}{v_{0}}$

where $h_{0}$ is initial (inlet) turbidity current thickness or the height of the inlet sluice gate, $u_{0}$ is initial velocity of the turbidity current in the flow direction, and $v_{0}$ is the initial flow kinematic viscosity. Also, in this table $R i_{0}$ is the initial flow Richardson number defined as,

$R i_{0}=\frac{g^{\prime}{ }_{0} h_{0} \cos \theta}{u_{0}^{2}}$,

where $g_{0}^{\prime}$ is the initial reduced gravitational acceleration, $\theta$ is the main channel angle made with horizontal axis, 
and $T$ denotes temperature of the clear water. Using this equation when $R i_{0}>1$, subcritical condition is reached and if $R i_{0}<1$, the flow becomes supercritical [34].

Considering the fact that the blend concentrations applied do not affect the water-coleon mixture viscosity much, the viscosity of the turbidity current is taken to be equal to that of water [10]. It is also noted that, in Eq. (2), the initial flow Reynolds number is found to be between 366,70 to 3027,34 . The initial Richardson number (in Eq. (3)) is between 0,0065 to 0,5782 .

\section{DIMENSIONAL ANALYSIS}

Using the Buckingham's $\Pi$ theorem and dimensional analysis, the dimensionless variables for the problem at hand can be derived as follows:

If the relationship between the effective independent variables for the lateral growth of turbidity current in each force balance regime (the force balance regimes proposed by the Tsihrintzis and Alavian [34] for spreading the density current) is considered, the following relation can be written,

$f_{1}\left(b, x, Q_{0}, B_{0}, b_{0}, h_{0}, \theta\right)=0$,

where, the subscript "0" denotes the initial value, and $B_{0}$ represents the initial buoyancy flux. Now, using the Buckingham's $\Pi$ theorem, the following dimensionless variables can be obtained:

$$
\begin{aligned}
& \pi_{1}=b^{1}\left(Q_{0}\right)^{b_{1}}\left(B_{0}\right)^{c_{1}}=b\left(Q_{0}\right)^{-3 / 5}\left(B_{0}\right)^{1 / 5}=\frac{b}{\left(Q_{0}^{3} / B_{0}\right)^{1 / 5}}=\frac{b}{l_{0}} \\
& \pi_{2}=x^{1}\left(Q_{0}\right)^{b_{2}}\left(B_{0}\right)^{c_{2}}=x\left(Q_{0}\right)^{-3 / 5}\left(B_{0}\right)^{1 / 5}=\frac{x}{\left(Q_{0}^{3} / B_{0}\right)^{1 / 5}}=\frac{x}{l_{0}} \\
& \pi_{3}=b_{0}^{1}\left(Q_{0}\right)^{b_{3}}\left(B_{0}\right)^{c_{3}}=b_{0}\left(Q_{0}\right)^{-3 / 5}\left(B_{0}\right)^{1 / 5}=\frac{b_{0}}{l_{0}} \\
& \pi_{4}=h_{0}^{1}\left(Q_{0}\right)^{b_{4}}\left(B_{0}\right)^{c_{4}}=h_{0}\left(Q_{0}\right)^{-3 / 5}\left(B_{0}\right)^{1 / 5}=\frac{h_{0}}{l_{0}} \\
& \pi_{5}=\theta^{1}\left(Q_{0}\right)^{b_{5}}\left(B_{0}\right)^{c_{5}}=\theta\left(Q_{0}\right)^{0}\left(B_{0}\right)^{0}=\theta
\end{aligned}
$$

therefore,

$$
f_{2}\left(\frac{b}{l_{0}}, \frac{x}{l_{0}}, \frac{b_{0}}{l_{0}}, \frac{h_{0}}{l_{0}}, \theta\right)=0
$$

In Eq. (5), $\left(b / l_{0}\right)$ is the dimensionless current width, $\left(x / l_{0}\right)$ is the dimensionless current length, $\left(b_{0} / l_{0}\right)$ is the dimensionless initial current width, $\left(h_{0} / l_{0}\right)$ is the dimensionless initial current thickness, and $\theta$ is the channel slope angle. In all the above relations, $l_{0}=\left(Q_{0}^{3} / B_{0}\right)^{1 / 5}$ is the initial buoyancy length scale. It is noted here that, $b_{0}$ and $h_{0}$ are different constants, then,

$$
f_{3}\left(\frac{b}{l_{0}}, \frac{x}{l_{0}}, \theta\right)=0
$$

Since $\theta$ (the channel slope angle) has very little effect on the dimensionless lateral growth $\left(b / l_{0}\right)$, then, in each of the force balance regime, we have,

$$
\begin{aligned}
& f_{4}\left(\frac{b}{l_{0}}, \frac{x}{l_{0}}\right)=0 \\
& \frac{b}{l_{0}}=f_{5}\left(\frac{x}{l_{0}}\right), \text { and } \\
& \frac{b}{l_{0}}=C_{1}\left(\frac{x}{l_{0}}\right)^{n} .
\end{aligned}
$$

Now, should $t$ be substituted for $x$ in Eq. (4), the equation takes the form,

$$
f_{1}\left(b, t, Q_{0}, B_{0}, b_{0}, h_{0}, \theta\right)=0,
$$

which results,

$$
\begin{aligned}
& \pi_{1}=b^{1}\left(Q_{0}\right)^{b_{1}}\left(B_{0}\right)^{c_{1}}=b\left(Q_{0}\right)^{-3 / 5}\left(B_{0}\right)^{1 / 5}=\frac{b}{l_{0}} \\
& \pi_{2}=t^{1}\left(Q_{0}\right)^{b_{2}}\left(B_{0}\right)^{c_{2}}=t\left(Q_{0}\right)^{-4 / 5}\left(B_{0}\right)^{3 / 5}=\frac{t}{t_{0}} \frac{1}{l_{0}^{2}} A_{0} \\
& \pi_{3}=b_{0}^{1}\left(Q_{0}\right)^{b_{3}}\left(B_{0}\right)^{c_{3}}=b_{0}\left(Q_{0}\right)^{-3 / 5}\left(B_{0}\right)^{1 / 5}=\frac{b_{0}}{l_{0}} \\
& \pi_{4}=h_{0}^{1}\left(Q_{0}\right)^{b_{4}}\left(B_{0}\right)^{c_{4}}=h_{0}\left(Q_{0}\right)^{-3 / 5}\left(B_{0}\right)^{1 / 5}=\frac{h_{0}}{l_{0}} \\
& \pi_{5}=\theta^{1}\left(Q_{0}\right)^{b_{5}}\left(B_{0}\right)^{c_{5}}=\theta\left(Q_{0}\right)^{0}\left(B_{0}\right)^{0}=\theta
\end{aligned}
$$

therefore,

$$
f_{2}\left(\frac{b}{l_{0}}, \frac{t}{l_{0}}, \frac{1}{l_{0}^{2}} A_{0}, \frac{b_{0}}{l_{0}}, \frac{h_{0}}{l_{0}}, \theta\right)=0
$$

In the above relations, $t_{0}=\left(Q_{0}^{3} / B_{0}\right)^{1 / 5} / U_{0}$ which is the initial buoyancy time scale. Finally, taking similar steps from Eq. (5) through (9), the following relation can be obtained:

$$
\frac{b}{l_{0}}=C_{2}\left(\frac{t}{l_{0}}\right)^{m}
$$

which, in fact, relates the dimensionless current width to the $m^{\text {th }}$ power of the dimensionless time with $C_{2}$ being a constant coefficient.

\section{$4 \quad$ RESULTS AND DISCUSSIONS}

In this study, the lateral growth of a turbulent unsteady supercritical inclined turbidity current is investigated based on the balance of forces experimentally. The work is performed for difference slopes of 1,2 , and $3 \%$ and three initial concentrations of $0,5,1$, and $1,5 \%$ and three initial volume fluxes of 10,15 , and $20 \mathrm{lit} / \mathrm{min}\left(1,66 \times 10^{-4}, 2,50 \times 10^{-4}\right.$, and $\left.3,33 \times 10^{-4} \mathrm{~m}^{3} / \mathrm{s}\right)$. 
The experimental results are normalized and plotted in the form of dimensionless graphs from which a theoretical model is obtained. The relative position of the nose of the turbidity current with respect to the source $(x)$ has been normalized with respect to the initial buoyancy length scale, $l_{0}=\left(Q_{0}^{3} / B_{0}\right)^{1 / 5}$. Also, for each $x$, the appropriate time $t$ has been normalized with respect to the initial buoyancy time scale, $t_{0}=\left(Q_{0}^{3} / B_{0}\right)^{1 / 5} / U_{0}$. To analyze the lateral growth, two types of graphs have been considered as follow.

\subsection{Position Related Lateral Growth}

Figs. 3 to 6 show the plots of dimensionless current width (hereinafter called current width) $\left(b / l_{0}\right)$ vs. dimensionless current length (hereinafter called current length) $\left(x / l_{0}\right)$ which relates the lateral growth of the turbidity current to its position. Fig. 3 shows the effect of variations of the initial volume flux on the dimensionless lateral growth (hereinafter called lateral growth) for two constant slopes of 1 and $3 \%$ for two different initial concentrations of $C_{0}=0,5$ and $C_{0}=1,5 \%$. Fig. 4 shows the effect of variations of the initial concentration on the lateral growth at a constant slope and initial volume flux. Fig. 5 shows the effect of variations of the slope of the channel bottom wall on the lateral growth at a constant initial concentration and a volume flux. Based on Figs. 3, 4 , and 5 , the rate of the lateral growth differs for $\left(x / l_{0}\right)<6$ (the regime hereinafter shown as $R_{1}$ ) and for $\left(x / l_{0}\right)>6$ (the regime hereinafter shown as $R_{2}$ ). Based on the plotted data in Figs. 3, 4, and 5, an equation of the form,

$$
\frac{b}{l_{0}}=C_{1}\left(\frac{x}{l_{0}}\right)^{n}
$$

can be fitted. In this equation $n$ is the slope of the lines in Figs. 3 to 6 , and $C_{1}$ is the unknown proportionality coefficient which can be determined from the experimental data. Based on the results obtained from the experimental runs, when the current length reaches about $6,\left(\left(x / l_{0}\right) \approx 6\right)$, the current width takes a value of about 3 , $\left(\left(b / l_{0}\right) \approx 3\right)$. These results indicate that the lateral growth in this region is independent of the slope, initial concentration, and initial volume flux variation. At $\left(x / l_{0}\right) \approx 6$, the slope changes, hence, the two regimes of $R_{1},\left(x / l_{0}\right)<6$, and $R_{2}$, $\left(x / l_{0}\right)>6$, can be clearly distinguished. Based on the plots obtained from the experimental results (Figs. 3 - 6), the lateral growth in $R_{1}$ and $R_{2}$ regimes differs from each other due to the difference in slopes of the plotted data in the regimes. This, in turn, indicates that the types of forces involved and their magnitudes in these regimes are different. It needs to be mentioned here that Tsihrintzis and Alavian [34] in their work distinguished different flow regimes based on the balancing of the driving and resisting forces in the latitudinal and longitudinal directions. In their work, for the supercritical initial flow and mild slope condition, they considered three regimes of inertia-viscous, buoyancyviscous, and gravity-viscous. In this present work, the condition for the supercritical initial flow with mild slope is taken to be the same as that of Tsihrintzis and Alavian [34].
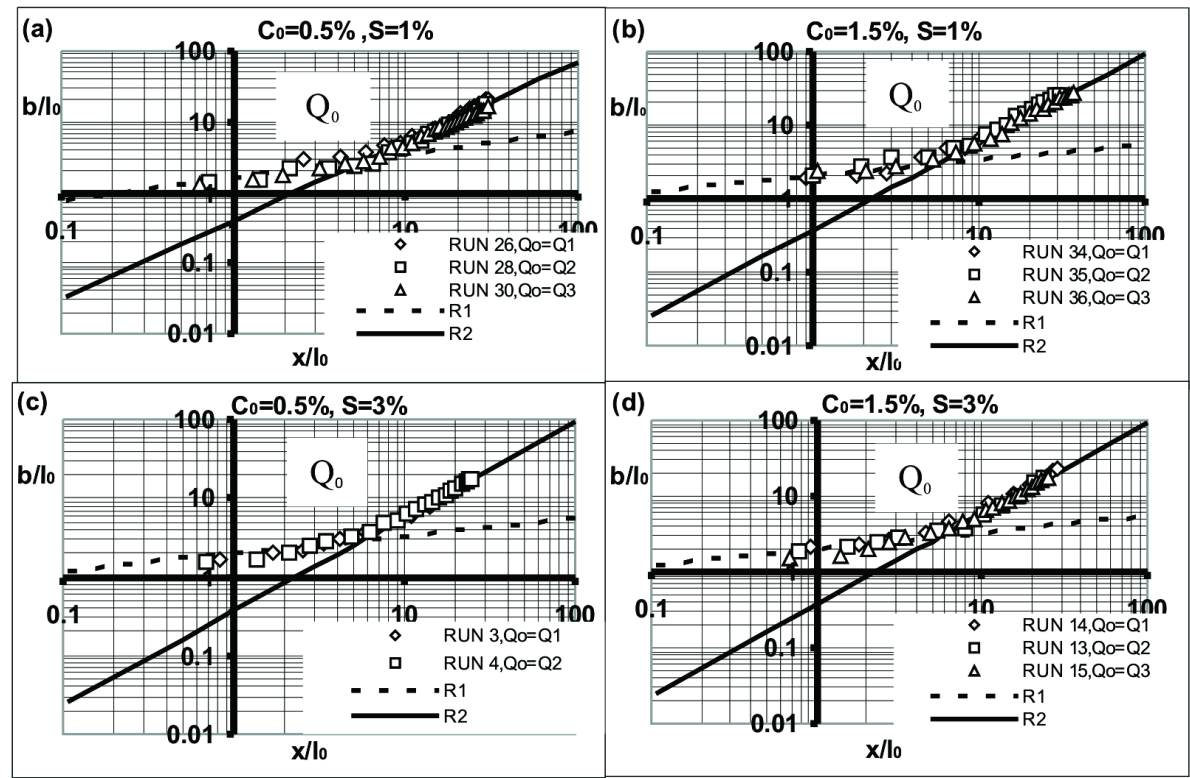

Figure 3 Initial volume flux variations for current width vs. current length for constant initial concentration and slope $\left(Q_{1}=1,66 \times 10^{-4}, Q_{2}=2,50 \times 10^{-4}\right.$, and $\left.Q_{3}=3,33 \times 10^{-4} \mathrm{~m}^{3} / \mathrm{s}\right)$.

From Figs. 3 - 6, it can be clearly observed that, there are two regimes within the latitudinal turbidity spreading current. The two regimes are the inertia-viscous and buoyancy-viscous. As it was mentioned before, however, there exists a third regime of gravity-viscous, $R_{3}$, which in the present work, it is not clearly visible. The reason being that, after the first and second regimes are developed, the turbidity current hits the main channel side walls, hence, the lateral growth can no longer be traced. For the mild slope, for the supercritical initial flow condition, inertia is a driving force and buoyancy is a resisting one. The initial balance of forces is for the inertia and viscous forces, regime $R_{1}$. An internal hydraulic jump occurs then, and the flow becomes subcritical, hence, the type of the balance of forces changes to a balance for buoyancy and viscous forces, 
regime $R_{2}$, for a small latitudinal spreading current. Then, the type of balance changes to a gravity-viscous forces

balance in $R_{3}$ regime.
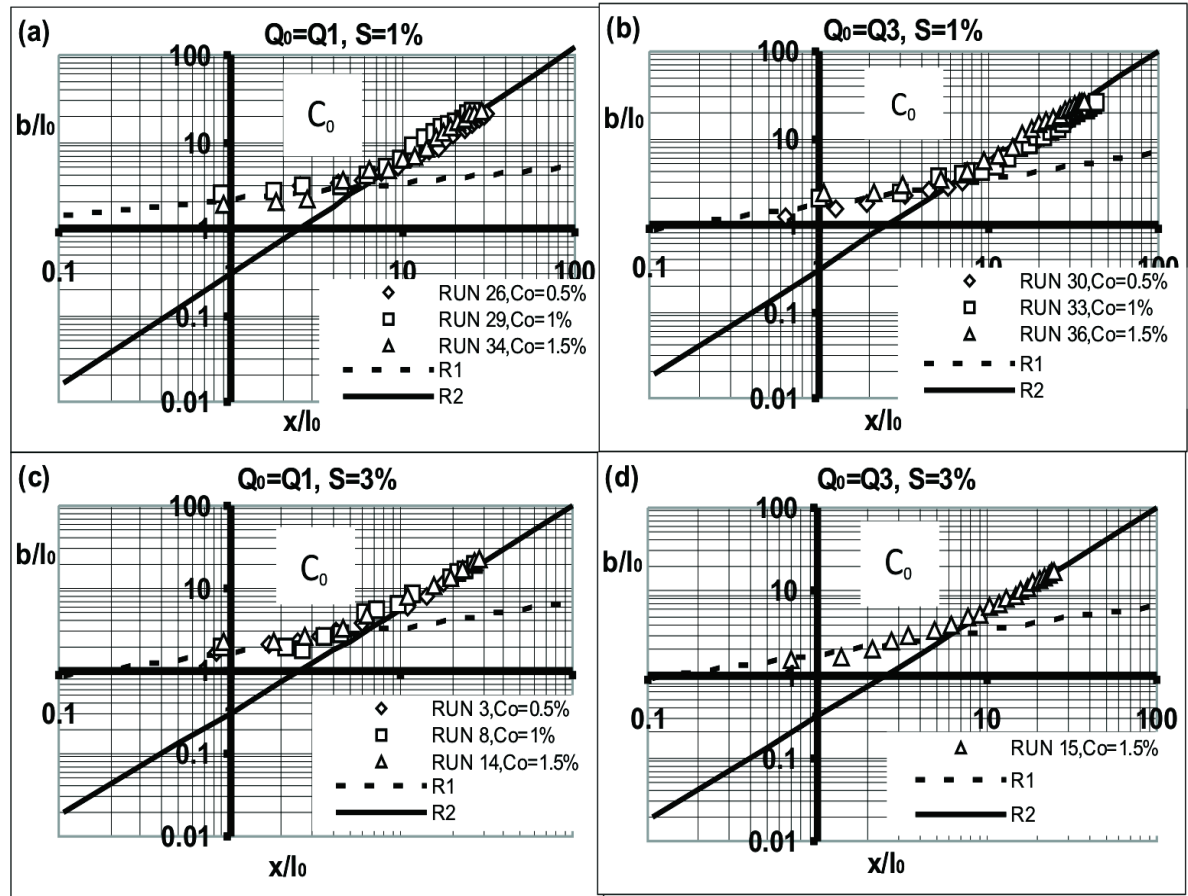

Figure 4 Initial concentration variations for current width vs. current length for constant initial volume flux and slope $\left(Q_{1}=1,66 \times 10^{-4}\right.$ and $\left.Q_{3}=3,33 \times 10^{-4} \mathrm{~m}^{3} / \mathrm{s}\right)$.
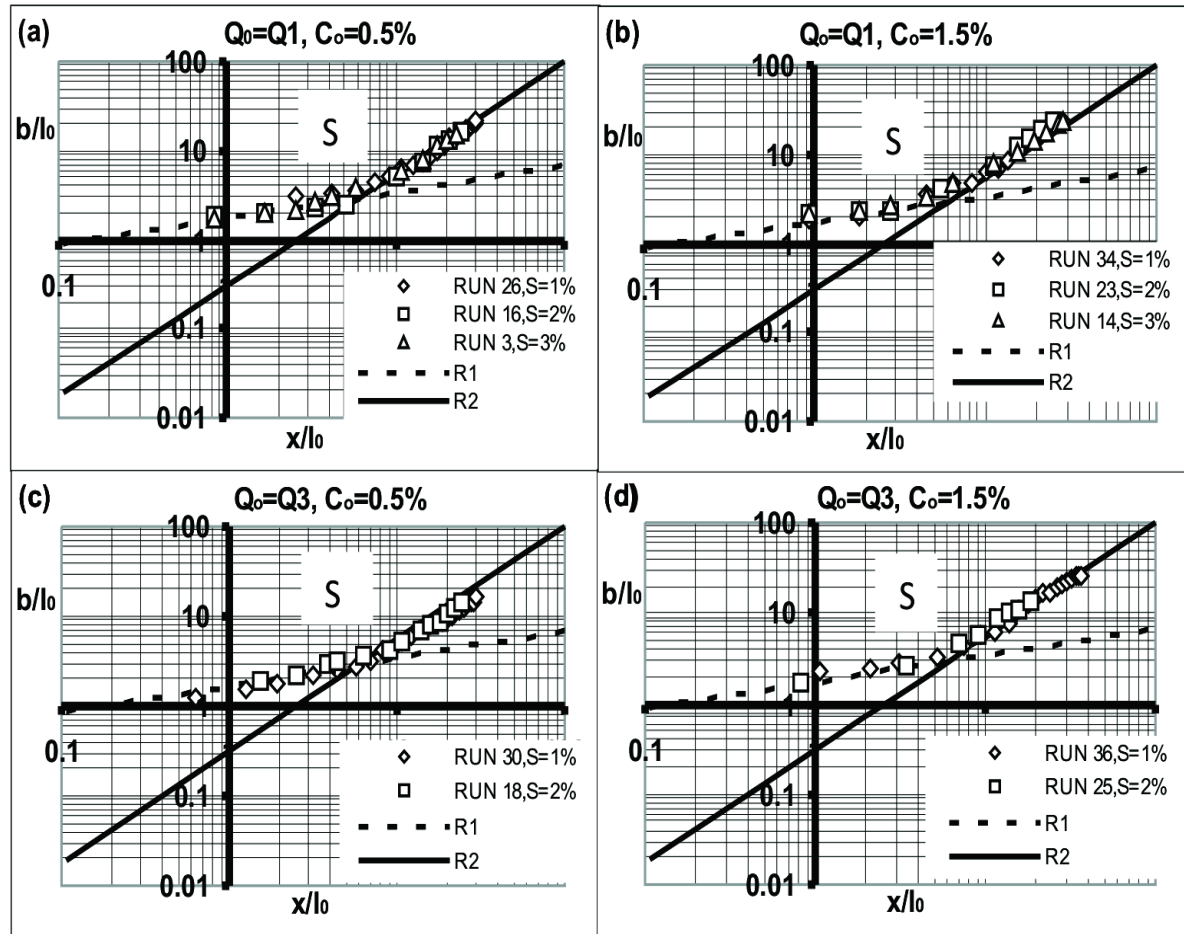

Figure 5 Main channel bottom surface slope variations for current width vs. current length for constant initial volume flux and initial concentration $\left(Q_{1}=1,66 \times 10^{-4}\right.$ and $\left.Q_{3}=3,33 \times 10^{-4} \mathrm{~m}^{3} / \mathrm{s}\right)$.

Based on the slope of the fitted line within Figs. 3 to 6 for each regime of the force balance, the lateral growth rate in $R_{1}$ is less than that in $R_{2}$, since the driving force is large and the resisting force is very small in $R_{1}$ regime. Therefore, the turbidity current accelerates and has less time for spreading. It should be mentioned here that the resisting force here is the drag force, and the driving force includes the inertia force and the component of the apparent weight in the flow direction. According to the aforementioned discussions, in $R_{2}$ regime, with changes of concentration and flow rate, the slope remains constant, but in $R_{1}$ regime, the slope changes due to the flow being supercritical and turbulent. This change of the slope is more pronounced for greater concentrations, higher volumetric flow rates, and steeper channel slopes. However, since in $R_{1}$ regime the channel slope changes 
and the concentrations variations do not significantly affect the obtained results, hence, the slope of the line passing through the obtained data can be considered to be constant. Now, according to Eq. (13), the measured width, $b$, with respect to $x$ (Fig. 2) obeys the following equation for both $R_{1}$ and $R_{2}$ regimes:

$b=C_{1}^{\prime} x^{n}$

where, $C_{1}^{\prime}$ is a proportionality constant, hence, $b$ changes with respect to $x^{n}$.

Fig. 6 illustrates the current width $\left(b / l_{0}\right)$ with respect to the current length $\left(x / l_{0}\right)$. From the plotted data in this figure, the best curve fit takes the form,

$$
\frac{b}{l_{0}}=1,77\left(\frac{x}{l_{0}}\right)^{0,38}
$$

for $R_{1}$ regime and takes the form,

$\frac{b}{l_{0}}=0,55\left(\frac{x}{l_{0}}\right)^{1,08}$,

for $R_{2}$ regime. Therefore, the lateral growth in $R_{1}$ and $R_{2}$ regimes is proportional to $x^{0,38}$ and $x^{1,08}$, respectively. However, these values in Tsihrintzys and Alavian [3] work, for the density current without particles (at similar conditions in the case of mild slope supercritical initial flow) are $x^{0,636}$ and $x^{0,200}$ for $R_{1}$ and $R_{2}$ regimes, respectively.

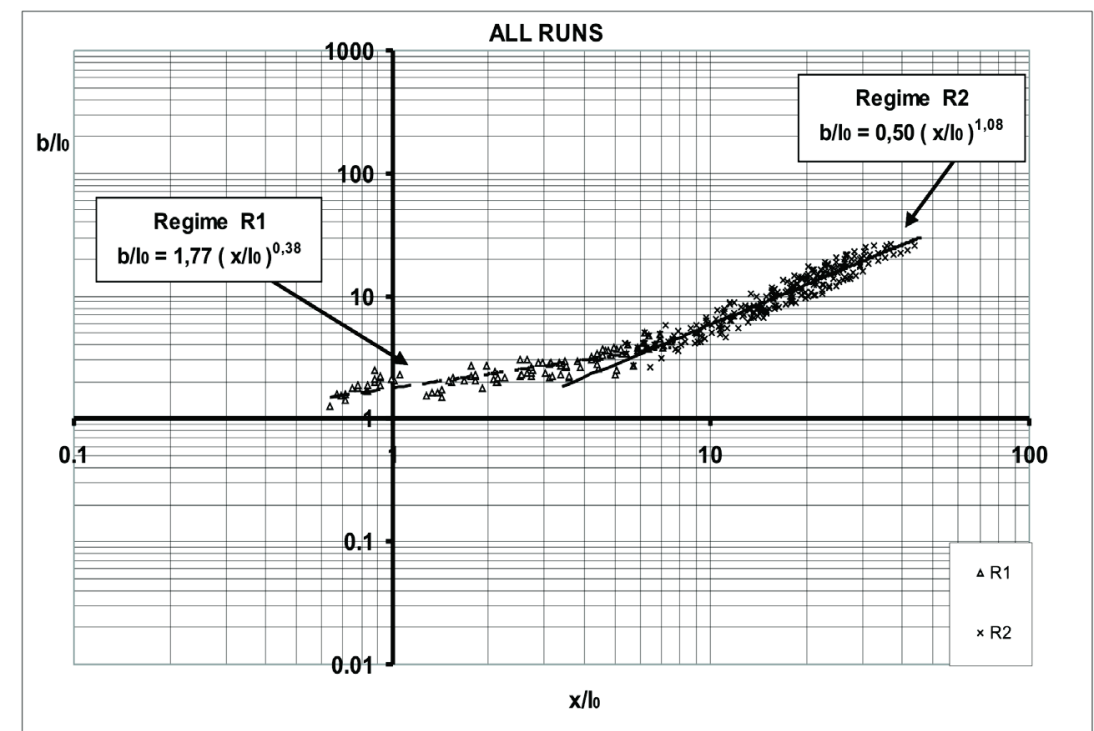

Figure 6 Regimes $R_{1}$ and $R_{2}$ best curve fit for current width vs. current length for all experimental runs
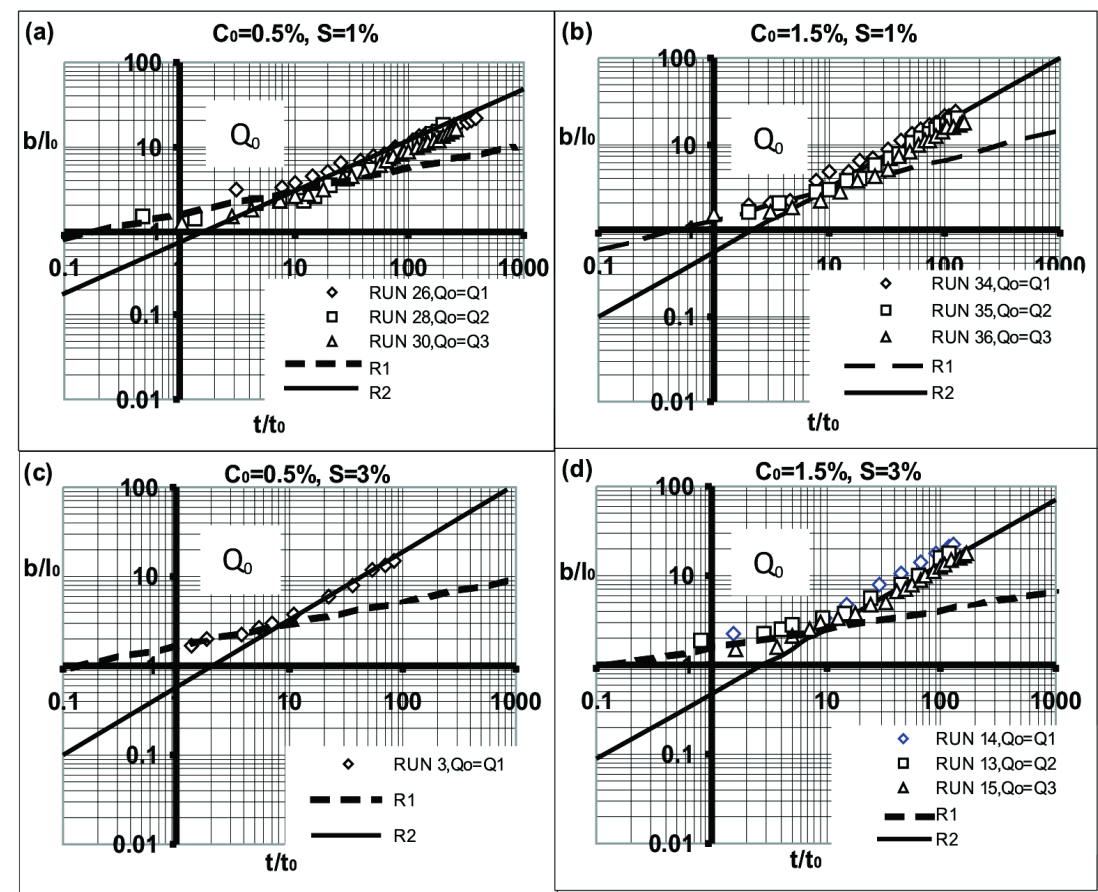

Figure 7 Initial volume flux variations for current width vs. time for constant initial concentration and slope $\left(Q_{1}=1,66 \times 10^{-4}, Q_{2}=2,50 \times 10^{-4}\right.$, and $\left.Q_{3}=3,33 \times 10^{-4} \mathrm{~m}^{3} / \mathrm{s}\right)$. 


\subsection{Time Related Lateral Growth}

Figs. 7 to 10 show plots of the current width $\left(b / l_{0}\right)$ vs. dimensionless time (hereinafter called time) $\left(t / t_{0}\right)$ which relates the lateral growth of the turbidity current to time. Fig. 7 shows the effect of variations of the initial volume flux on the lateral growth for two constant slopes of 1 and $3 \%$ for two different initial concentrations of $C_{0}=0,5$ and $C_{0}=1,5 \%$. Fig. 8 shows the effect of variations of the initial concentration on the lateral growth at a constant slope and an initial volume flux. Fig. 9 shows the effect of variations of the slope of the channel bottom wall on the lateral growth at a constant initial concentration and an initial volume flux. Based on Figs. 7, 8, and 9, the rate of the lateral growth differs for $\left(t / t_{0}\right)<10$ (the regimes hereinafter shown as $R_{1}$ ) and for $\left(t / t_{0}\right)>10$ (the regimes hereinafter shown as $R_{2}$ ).

Based on the plotted data in Figs. 7, 8, and 9, an equation of the form,

$$
\frac{b}{l_{0}}=C_{2}\left(\frac{t}{l_{0}}\right)^{m}
$$

can be obtained. In this equation $\mathrm{m}$ is the slope of the lines in Figs. 7 to 10 , and $C_{2}$ is the unknown proportionality coefficient which can be determined from the experimental data. Based on the results obtained from the experimental runs, when the dimensionless length reaches about 10, $\left(\left(t / t_{0}\right)\right.$ $\approx 10$ ), the dimensionless width takes a value of about 3 , $\left(\left(b / l_{0}\right) \approx 3\right)$. These results indicate that the lateral growth in this region is independent of the slope, concentration, and volumetric flow rate variations.

At $\left(t / t_{0}\right) \approx 10$, the slope changes, hence, the two regimes of $R_{1},\left(\left(t / t_{0}\right)<10\right)$, and $R_{2},\left(\left(t / t_{0}\right)>10\right)$, can be clearly distinguished. Based on the plots obtained from the experimental results (Figs. 7-10), the lateral growth in $R_{1}$ and $R_{2}$ regimes differs from each other due to the difference in slopes of the plotted data in the regimes. This, in turn, indicates that, like the position related lateral growth case, the types of the forces involved and their magnitudes in these regimes are different.

It needs to be mentioned here that Tsihrintzis and Alavian [34], in their work, distinguished different flow regimes based on the balancing of the driving and resisting forces in the latitudinal and longitudinal flow directions. In their work, for the supercritical mild condition, they considered three regimes of inertia-viscous, buoyancyviscous, and gravity-viscous. In the present work, the conditions for the mild slope supercritical initial flow are similar to those of Tsihrintzis and Alavian [34]. From Figs. $7-10$, it can be clearly observed that there are two regimes within the latitudinal turbidity spreading current. They are the inertia-viscous and buoyancy-viscous regimes. As it was mentioned before, similar to the position related lateral growth, there exists a third regime of gravity-viscous, $R_{3}$, which in the present work, it is not clearly visible. The reason being that, after the first and second regimes are developed, the turbidity current hits the main channel side walls, hence, the lateral growth can no longer be traced. In the case of mild slope with supercritical initial flow, inertia is a driving force and buoyancy is a resisting one. The initial balance of forces is for the inertia and viscous forces, regime $R_{1}$. An internal hydraulic jump occurs then, and the flow becomes subcritical, hence, the type of the balance of forces changes to a balance for buoyancy and viscous forces, regime $R_{2}$, for a small latitudinal spreading current. Then, the type of balance changes to a gravity-viscous forces in $R_{3}$ regime.
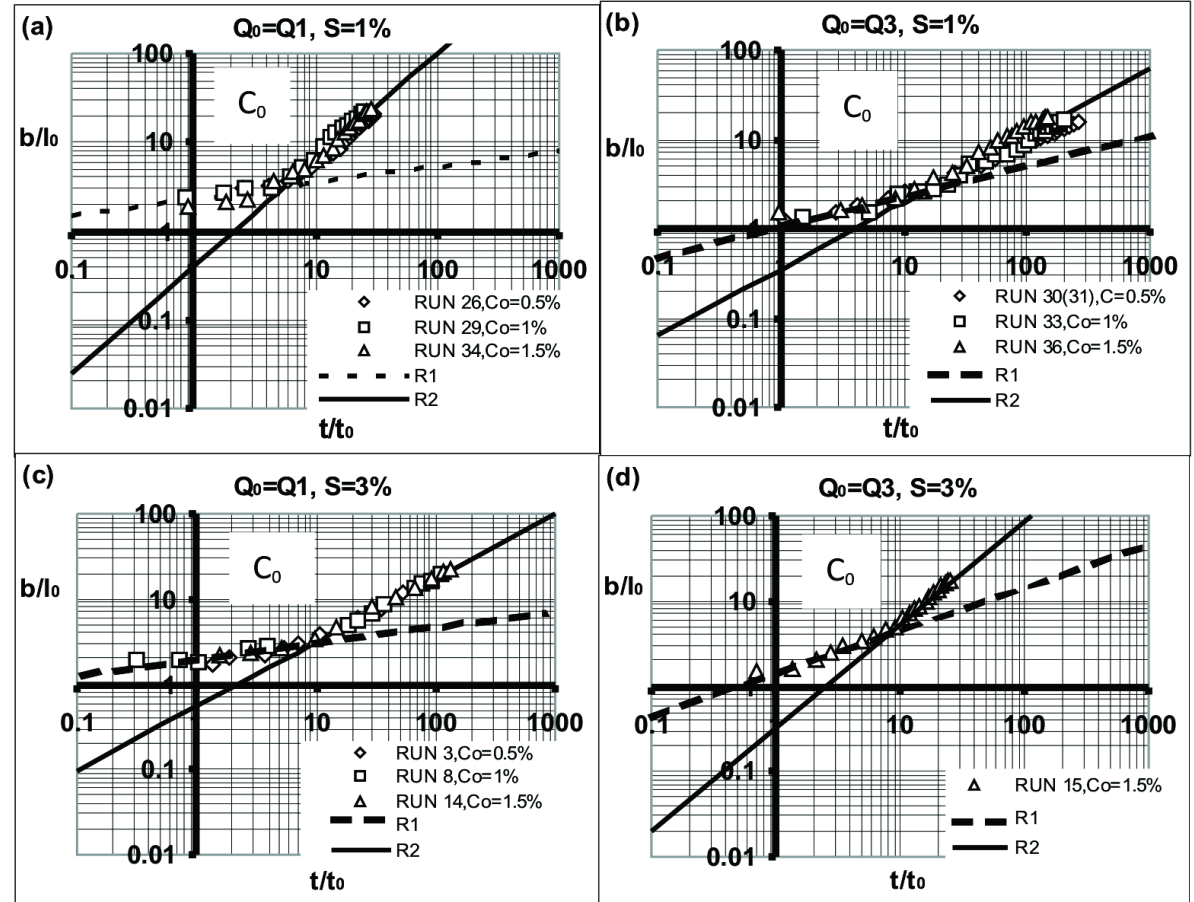

Figure 8 Initial concentration variations for current width vs. time for constant initial volume flux and slope $\left(Q_{1}=1,66 \times 10^{-4}\right.$ and $\left.Q_{3}=3,33 \times 10^{-4} \mathrm{~m}^{3} / \mathrm{s}\right)$ 

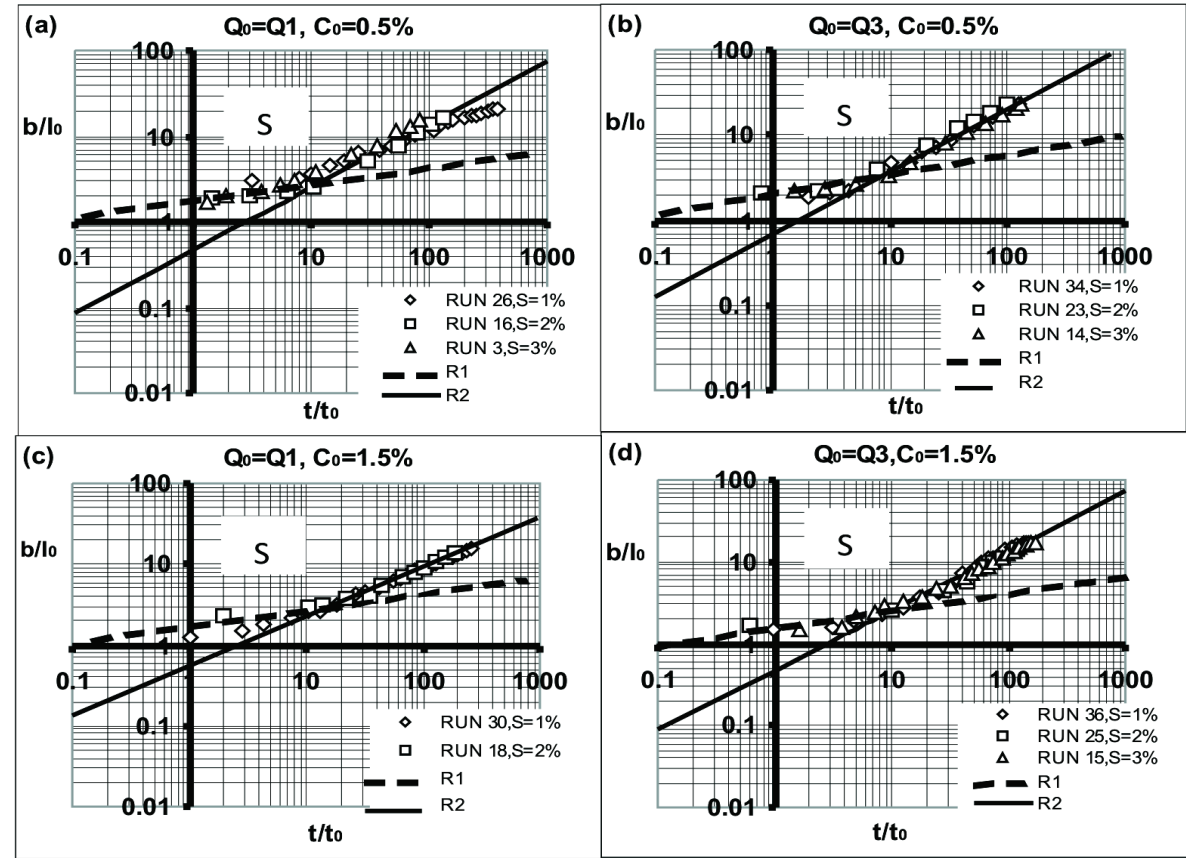

Figure 9 Main channel bottom surface slope variations for current width vs. time for constant initial volume flux and initial concentration $\left(Q_{1}=1,66 \times 10^{-4}\right.$ and $\left.Q_{3}=3,33 \times 10^{-4} \mathrm{~m}^{3} / \mathrm{s}\right)$.

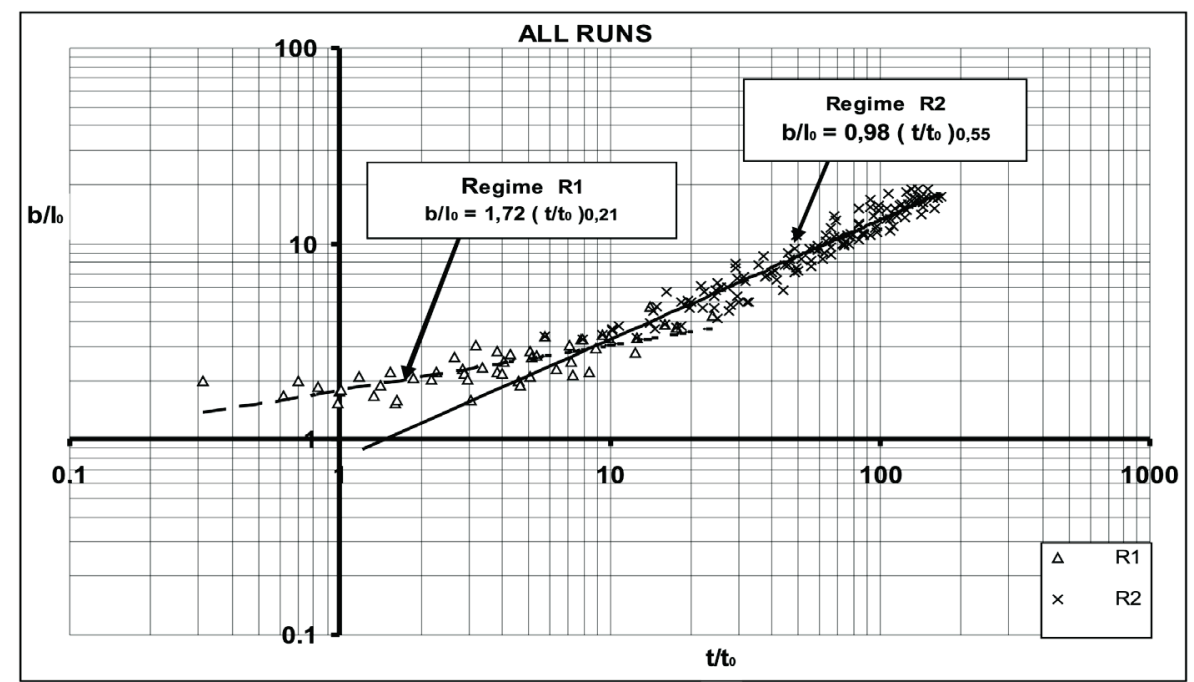

Figure 10 Regimes $R_{1}$ and $R_{2}$ best curve fit for current width vs. time for all experimental runs

Based on the slope of the fitted line within Figs. 7-10 for each regime of the force balance, the lateral growth rate in $R_{1}$ is less than that in $R_{2}$, since the driving force is large and the resisting force is very small in $R_{1}$ regime. Therefore, the turbidity current accelerates and has less time for spreading. It should be mentioned here that the resisting force here is the drag force and the driving force includes the inertia force and the component of the apparent weight in the flow direction. According to the aforementioned discussions, in $R_{2}$ regime, with changes of concentration and flow rate, the slope remains constant, but in $R_{1}$ regime, the slope changes due to the flow being supercritical and turbulent. This change of the slope is more pronounced for the greater concentrations, higher volumetric flow rates, and steeper channel slopes. However, since in $R_{1}$ regime the channel slope changes and the concentrations variations do not significantly affect the obtained results, hence, the slope of the line passing through the obtained data can be considered to be constant. Now, according to Eq. (17), the measured width, $b$, with respect to $t$ (Fig. 2) obeys the following equation for both $R_{1}$ and $R_{2}$ regimes:

$b=C_{2}^{\prime} t^{m}$

where, $C_{2}^{\prime}$ is a constant, hence, $b$ changes with respect to $t^{m}$. Fig. 10 illustrates the current width $\left(b / l_{0}\right)$ with respect to the current length $\left(x / l_{0}\right)$. From the plotted data in this figure, the best curve fit can take the form

$$
\frac{b}{l_{0}}=1,72\left(\frac{t}{l_{0}}\right)^{0,21}
$$

for $R_{1}$ regime and takes the form,

$$
\frac{b}{l_{0}}=0,98\left(\frac{t}{l_{0}}\right)^{0,55}
$$


for $R_{2}$ regime. Therefore, the lateral growth in $R_{1}$ and $R_{2}$ regimes is proportional to $t^{0,21}$ and $t^{0,55}$, respectively.

\section{CONCLUSIONS}

In this study, lateral growth of an unsteady turbulent inclined turbidity current has been investigated. The following conclusions can be drawn:

- Based on the experimental results obtained, in the graphs of position as well as time related lateral growth, two regimes of $\mathrm{R} 1$ and $\mathrm{R} 2$ are detectable in which the lateral growth rate in those two regimes is different. Also, there exists a third regime, $R_{3}$, in which the lateral growth cannot be observed due to the contact of the current with the main channel side walls.

- In the graphs of the position related lateral growth, the rate of the lateral growth is different for $\left(x / l_{0}\right)>6$ than that for $\left(x / l_{0}\right)<6$. Similarly, in graphs of the time related lateral growth, the rate of the lateral growth is different for $\left(t / t_{0}\right)<10$ than that for $\left(t / t_{0}\right)>10$. This indicates that the magnitude and the types of forces in those two regimes are different.

- It is found that the rate of the lateral growth in regime $R_{2}$ is more than that in $R_{1}$ because of the greater driving force in $R_{1}$ regime, which causes less time for the current to spread out.

- In graphs of the position related lateral growth, when the current length reaches $\left(x / l_{0}\right) \approx 6$, the current width takes $\left(b / l_{0}\right) \approx 3$. This shows that, the lateral growth in this particular region is independent of the slope, concentration and volumetric flow rate variations.

- In graphs of the time related lateral growth, when the current length reaches $\left(t / t_{0}\right) \approx 10$, the current width takes $\left(b / l_{0}\right) \approx 3$. This shows that the lateral growth in this particular region is independent of the slope, concentration, and volumetric flow rate variations.

- The experimental results show that there exists a nonlinear single coefficient relation between the lateral growth of turbidity current and position as well as between the lateral growth of turbidity current and time.

- In the case of the mild slope for supercritical inlet flow, for the turbidity current, the lateral growth in $R_{1}$ and $R_{2}$ regimes, is proportional to $t^{0,21}$ and, $t^{0,55}$ and also, to $x^{0,38}$ and, $x^{1,08}$ respectively.

\section{ACKNOWLEDGMENTS}

The authors would like to express their gratitudes to prof. Rad and prof. firoozababadi from Sharif university of technology for their very valuable assistance.

\section{REFERENCES}

[1] Simpson, J. E. (1987). Gravity currents in the environment and the laboratory. Ellis Harwood, Chi Chester, U. K.

[2] Hartel, C., Meiburg, E., \& Necker, F. (2000). Analysis and Direct Numerical Simulation of the Flow at a GravityCurrent Head. Part 1. Flow topology and front Speed for Slip and no-Slip Boundaries. J. Fluid Mech., 418, 189-212. https://doi.org/10.1017/S0022112000001221

[3] Hay, A. E. (1987). Turbidity currents and submarine channel formation in Rupert inlet. J. Geophys. Res., 92, 2883-2900. https://doi.org/10.1029/JC092iC03p02883

[4] Salaheldin, T. M., Imran, J., Chaudhry, M. H, \& Reed, C. (2000). Role of fine-grained sediment in turbidity current flow dynamics and resulting deposits. Marine Geology, 171, 21-38. https://doi.org/10.1016/S0025-3227(00)00114-6

[5] Ellison, T. H. \& Turner, J. S. (1959). Turbulent entrainment in stratified flows. J. Fluid Mech., 6, 423-448. https://doi.org/10.1017/S0022112059000738

[6] Middleton, G. V. (1966). Experiments on density and turbidity currents. Can. J. Earth Sci., 3(4), 523-546. https://doi.org/10.1139/e66-038

[7] Britter, R. E. \& Linden, P. F. (1980). The motion of the front of a gravity current traveling down an incline. J. Fluid Mech., 91, 531-543. https://doi.org/10.1017/S0022112080000754

[8] Garcia, M. \& Parker, G. (1991). Experiment of bed sediment into suspension. J. Hyd. Eng., 117, 414-435. https://doi.org/10.1061/(ASCE)0733-9429(1991)117:4(414)

[9] Garcia, M. H. \& Parker, G. (1993). Experiments on the entrainment of sediment into suspension by dense bottom current. J. Geophys. Res., 98, pp. 4793-4807. https://doi.org/10.1029/92JC02404

[10] Garcia, M. H. (1994). Depositional turbidity currents laden with poorly sorted sediment. J. Hydr. Eng., 120(11), 12401263. https://doi.org/10.1061/(ASCE)0733-9429(1994)120:11(1240)

[11] Altinakar, M. S., Graf, W. H., \& Hopfinger, E. J. (1996). Flow structure in turbidity currents. J. Hydr. Res., 34, 713718. https://doi.org/10.1080/00221689609498467

[12] Kneller, B. C., Bennett, S. J., \& McCaffrey, W. D. (1997). Velocity and turbulence structure of gravity currents and internal solitary waves. Sediment. Geol., 122, 235-250. https://doi.org/10.1016/S0037-0738(97)00031-6

[13] Kneller, B. C., Bennett, S. J., \& McCaffrey, W. D. (1999) Velocity structure, turbulence and fluid stresses in experimental gravity currents. J. Geophys. Res., 104, 52815291. https://doi.org/10.1029/1998JC900077

[14] Kneller, B. C. \& Buckee, C. (2000). The structure and fluid mechanics of turbidity currents. Sedimentology, 47, 62-94. https://doi.org/0.1046/j.1365-3091.2000.047s1062.x

[15] Buckee, C., Kneller, B., \& Peakall, J. (2001). Turbulence structure in steady, solute-driven gravity currents. Spec. Publ. Int. Assoc. Sediment, 173-189. https://doi.org/10.1002/9781444304275.ch13

[16] Sequeiros, O. E., Spinewine, B., Beaubouef, R. T., Sun, T., García, M. H., \& Parker, G. (2010). Characteristics of Velocity and Excess Density Profiles of Saline Underflows and Turbidity Currents Flowing over a Mobile Bed. Journal of Hydraulic Engineering, 136(7). https://doi.org/10.1061/ (ASCE) HY.1943-7900.0000200

[17] Ungarish, M., Mériaux, C. A., \& Kurz-Besson, C. B. (2014). The propagation of gravity currents in a $\mathrm{V}$-shaped triangular cross-section channel: experiments and theory. J. Fluid Mech., 754, 232-249. https://doi.org/10.1017/jfm.2014.396

[18] Tilston, M., Arrnot, R. W. C., Rennie, C. D., \& Long, B. (2015). The influence of grain size on the velocity and sediment concentration profiles and depositional record of turbidity currents. Geology, 43(9), 839-842. https://doi.org/10.1130/G37069.1

[19] Varjavand, P., Ghomeshi, M., Hosseinzadeh Dalir, A., Farsadizadeh, D., \& Docheshmeh Gorgij, A. (2015). Experimental observation of saline underflows and turbidity currents, flowing over rough beds. Canadian Journal of Civil Engineering, 42(11), 834-844. https://doi.org/10.1139/cjce-2014-0537

[20] Chamoun, S., De Cesare, G., \& Schleiss, A. J. (2016). Experimental investigation on turbidity current venting under restrained outflow discharges. Proceedings of River Flow, 1435-1441. https://doi.org/10.1201/9781315644479-227

[21] Chamoun, S., Zordan, J., De Cesare, G., \& Franca, M. J. 
(2016). Measurement of the deposition of fine sediments in a channel bed. Flow Measurement and Instrumentation, 50, 49-56. https://doi.org/10.1016/j.flowmeasinst.2016.06.008

[22] Steel, E., Buttles, J., Simms, A. R., Mohrig, D., Meiburg, E. (2016). The role of buoyancy reversal in turbidite deposition and submarine fan geometry. Geology, 44(12). https://doi.org/10.1130/G38446.1

[23] Asghari Pari, S. A., Kashefipour, S. M., \& Ghomeshi, M. (2016). An experimental study to determine the obstacle height required for the control of subcritical and supercritical gravity currents. European Journal of Environmental and Civil Engineering, 1-13. https://doi.org/10.1080/19648189.2016.1144537

[24] Ho, C. K., Christian, J. M., Ching, E.J., Slavin, J., Ortega, J., Murray, R., \& Rossman, L. A. (2016). Sediment Resuspension and Transport in Water Distribution Storage Tanks. American Water Works Association, 108(6), E349E361. https://doi.org/10.5942/jawwa.2016.108.0077

[25] Stagnaro, M. \& Bolla Pittaluga, M. (2014). Velocity and concentration profiles of saline and turbidity currents flowing in a straight channel under quasi-uniform conditions. Earth Surf. Dynam. 2, 167-180. https://doi.org/10.5194/esurf-2-167-2014

[26] Fan, J. \& Morris, G. (1992). Reservoir Sedimentation II: Reservoir Desiltation and Long Term Storage Capacity. J. of Hydraulic Eng., 118(3), 370-384 https://doi.org/10.1061/(ASCE)0733-9429

[27] Fan, J. \& Morris, G. (1992). Reservoir sedimentation I: Delta and density current deposits. J. Hydraulic Eng., 118(3), 354369. https://doi.org/10.1061/(ASCE)0733-9429

[28] Saguaro, M. \& Pittaluga, M. B. (2014). Velocity and concentration profiles of saline and turbidity currents flowing in a straight channel under quasi-uniform conditions. Earth Surf. Dynam., 2, 167-180. https://doi.org/10.5194/esurf-2-167-2014.

[29] Fietz, T. R. \& Wood, I. R. (1967). Three-dimensional density current. ASCE J. Hydraulics Div., 93(6)(HY6), 1-24.

[30] Alavian, V. (1986). Behavior of density current on an incline. ASCE Journal of Hydraulic Engineering, 112, 27-42 https://doi.org/10.1061/(ASCE)0733-9429

[31] Tsihrintzis, V. A. (1988). Theoretical and experimental investigation of three-dimensional boundary-attached density currents. PhD Thesis, Dept. Civil. Engrg, Univ. of Illinois, Urbana, Ill., USA.

[32] Christodoulou, G. C. \& Tzachou, F. E. (1994). Experiments on 3-D density currents. Preprints $4^{\text {th }}$ Intern. Symposium on Stratified Flows, 3 Grenoble, France.

[33] Choi, S. U. (1999). Bidirectional spreading of gravity underflows on an incline. Korea Water Resources Assoc., 32(2), 83-94.

[34] Tsihrintzis, V. A., Alavian, V. (1996). Spreading of threedimensional inclined gravity plumes. Journal of Hydraulic Research, 34, pp. 695-711. https://doi.org/10.1080/00221689609498466

[35] Christodoulou, G. C. (2001). Lateral Growth of 3-D Density Currents. Proceedings of the Congress International Association for Hydraulic Research, Netherlands.

[36] Choi, S.-U. Garcia, M. (2001). Spreading of gravity plumes on an incline. Coast. Eng. J. 43, 221. https://doi.org/10.1142/S0578563401000359

\section{$7 \quad$ Nomenclature}

$\mathrm{A}_{0}$ - cross-sectional area of inlet sluice gate $\left(\mathrm{m}^{2}\right)$

$b$ - maximum width of turbidity current (m)

$b_{0}$ - width of sluice gate or initial (inlet) width of turbidity current $(\mathrm{m})$

$B_{0}$ - initial buoyancy flux $\left(\mathrm{m}^{4} / \mathrm{s}^{3}\right)$

$C_{0}$ - inlet mixed weight concentration

$g$ - gravitational acceleration $\left(\mathrm{m} / \mathrm{s}^{2}\right)$ $g^{\prime}$ - reduced gravitational acceleration $g\left(\rho-\rho_{\mathrm{w}}\right) / \rho_{\mathrm{w}},\left(\mathrm{m} / \mathrm{s}^{2}\right)$

$g_{0}^{\prime}$ - initial reduced gravitational acceleration $\left(\mathrm{m} / \mathrm{s}^{2}\right)$

$h$ - turbidity current thickness (m)

$h_{0}$ - initial (inlet) turbidity current thickness or height of inlet sluice gate $(\mathrm{m})$

$l_{0}$ - initial buoyancy length scale $l_{0}=\left(Q_{0}^{3} / B_{0}\right)^{1 / 5}$,

$Q$ - volume flux $\left(\mathrm{m}^{3} / \mathrm{s}\right)$

$Q_{0}$ - initial (inlet) volume flux $\left(\mathrm{m}^{3} / \mathrm{s}\right)$

$R e_{0}$ - initial (inlet) flow Reynolds number

$R i_{0}$ - initial (inlet) flow Richardson number

$S$ - slope

$t$ - time taken for maximum longitudinal distance (s)

$t_{0}$ - initial buoyancy time scale, $t_{0}=\left(Q_{0}^{3} / B_{0}\right)^{1 / 5} / U_{0}$, (s)

$T$ - temperature $\left({ }^{\circ} \mathrm{C}\right)$

$U_{0}, u_{0}$ - initial (inlet) velocity of the turbidity current $(\mathrm{m} / \mathrm{s})$

$w_{\mathrm{c}}$ - caloen weight $(\mathrm{N})$

$w_{\mathrm{w}}$ - water weight $(\mathrm{N})$

$x$ - maximum longitudinal distance from source $(\mathrm{m})$

$\rho$ - density of turbidity current $\left(\mathrm{kg} / \mathrm{m}^{3}\right)$

$\rho_{\mathrm{w}}$ - density of water $\left(\mathrm{kg} / \mathrm{m}^{3}\right)$

$\theta$ - bed angle or main channel slope angle

$v_{0}$ - initial (inlet) kinematic viscosity $\left(\mathrm{m}^{2} / \mathrm{s}\right)$

\section{Contact information}

Mohammad Reza MOOSSAVI-HEKMATI, PhD, Student

Department of Mechanical and Aerospace Engineering,

Science and Research Branch, Islamic Azad University,

Tehran, Iran, 1477893855

E-mail: smrmhekmati@gmail.com

Tel.: +9829 44868536, Fax: +982944868536

Mohammad NAJAFI, Associate Professor

Corresponding author

Department of Mechanical and Aerospace Engineering

Science and Research Branch, Islamic Azad University,

Tehran, Iran, 1477893855

E-mail:m.njafi36@gmail.com

Tel.: +98 29 44868536, Fax: +982944868536 